\title{
Planning, Implementing, and Assessing an OER Faculty Learning Community: A Facilitator's Lens
}

\author{
Mary Jo Orzech \\ Drake Memorial Library \\ SUNY Brockport
}

Correspondence:

M. J. Orzech

Scholarly Communications Librarian

Drake Memorial Library

SUNY Brockport

Email: morzech at brockport.edu

\begin{abstract}
A librarian-led Faculty Learning Community (FLC) focused on Open Educational Resources (OER) can be a practical, low risk way to sustain campusbased OER programs during and after initial startup. Creating a space for sharing teaching successes and challenges is an important goal in the iterative journey toward open. The experiences and trust fostered in an FLC can help grow awareness of and commitment to adopting, deepening, and expanding a culture of openness. FLCs provide an opportunity to lean into open that enhances cross-campus relationships, identifies gaps, and emphasizes collegiality while moving toward enriched teaching and learning. They provide a launching point for sharing pedagogical practice, and a valuable venue for new ideas. Key strategies for planning, implementing, and assessing a multidisciplinary OER faculty learning community are highlighted. Practical advice is emphasized to support successful outcomes that can be easily replicated. Ten top takeaways are summarized from a year spent facilitating an OER FLC in a four-year, public, comprehensive college that included the shift to online courses during the COVID-19 pandemic, and it concludes with suggested next steps for continuing the OER conversation among faculty, students, librarians, instructional designers, teaching and learning center staff, administration, and other stakeholders.
\end{abstract}

Keywords: open educational resources, OER, faculty learning community, community of practice 


\section{Introduction}

The world of OER is growing fast and can be overwhelming for newcomers. Getting started with OER, an instructor may feel like a lone voice in the wilderness. Like-minded faculty can provide community and opportunity to voice questions, concerns, problems, and solutions with others in a safe space and provide needed insight for improving pedagogical practice. Embedding OER within a faculty learning community marries these two efforts to foster increased understanding, engagement, and growth.

An FLC provides an in-depth way to host a sustained discussion on a topic. FLCs have been defined as "a cross-disciplinary faculty and staff group who engage in an active, collaborative, yearlong program with a curriculum about enhancing teaching and learning. It includes frequent seminars and activities that provide learning, development, the scholarship of teaching, and community building" (Cox, 2004, p. 8).

This article provides an overview of an OER FLC from a facilitator's perspective. This lens focuses on bridging individual faculty development needs and institutional goals. A librarian led OER FLC specifically devoted to incorporating open teaching materials into college courses has many advantages. In this case, "materials" are all encompassing and include textbooks, videos, online sources and more. An FLC can be adapted to OER in any part of the instructional life cycle. Exploring some of the major dos and don'ts for planning, implementing, and assessing a multidisciplinary OER FLC can help those doing similar work.

The project was part of an OER sustainability plan at a four-year public comprehensive college in its third year of a large statewide initiative to improve course material affordability. It involved faculty with different knowledge, experience, and comfort level with OER. Keeping the conversation going was important to ensure the program continued to develop, grow, and thrive.

\section{Literature}

FLCs have been in existence for over four decades (Faculty Learning Communities, n.d.). OER have been developing in different venues and under different names for nearly as long or longer. OER are "teaching, learning, and research materials that are either in the public domain or licensed in a manner that provides everyone with free and perpetual permission to engage in the $5 R$ activities." (Creative Commons, n.d.). The $5 R$ s include being able to retain, reuse, revise, remix and redistribute materials (Wiley, n.d.).

OER programs may be particularly appropriate as a topic oriented FLC because they embrace members from multiple disciplines working on a common theme or methodology -- value comes from the variety of voices. FLCs typically include eight to twelve members who voluntarily agree to participate (Cox, 2001).

While sharing some common characteristics, FLCs are distinct from academic committees (Ortquist-Ahrens \& Torosyan, 2008, p. 7), as well as learning circles (Peer2Peer University, 2015; Pikula, 2018), faculty guilds (Lumen, 2020), project-based teams, support groups, leadership fellow programs (SPARC, n.d.), and other communities of practice (Wenger, 1998). Related phrases are also being used by some companies to offer services, e.g., Lumen Learning Circles. Some naming conventions are regional or consortial; others are based on the 
tradition at an institution, and some have more obscure etiology. Some groups are temporary in nature, and others are established, ongoing entities. The FLC model typically emphasizes pedagogical growth and development for faculty.

An FLC can be adapted for any college or university. Many institutions have already found the intersection of OER and FLCs to be useful for building a peer support infrastructure. These colleges include: Boise State University (Boise State, 2018), California State University (Soodjinda, Parker, Ross, \& Meyer, 2014), Grand Valley State University (Grand Valley State University, 2019), Metropolitan State University of Denver (Metropolitan State University of Denver, 2019), and Miami University of Ohio (Beazley, Haynes, Myers, \& Resnis, 2019; Bazeley, Waller, \& Resnis, 2014), among others.

There were similarities and differences among the programs. Each considered the institutional goals, campus culture, and academic and technological trends at the time. A University of British Columbia group, Open BC, has published an extensive library of teaching, support, and advocacy material online to help others. This includes a support staff working group guide, faculty OER toolkit, and accessibility toolkit (BC Open Ed, 2019).

As outlined by Cox (2004), necessary qualities for building a successful faculty community include "safety and trust, openness, respect, responsiveness, collaboration, relevance, challenge, enjoyment, esprit de corps, and empowerment". These qualities naturally resonate with both libraries and OER, making an OER FLC an especially strong candidate for library involvement. There is plenty of opportunity for collaboration at the intersection of teaching, support, and technology.

Librarians are increasingly being called on to participate and lead FLCs as their roles have expanded beyond the confines of library walls (Burress, Mann, \& Neville, 2020). Librarians are taking on additional responsibilities and can be especially well-suited in facilitating FLCs. At times, they may assume blended responsibilities as librarians, educators, coordinators, and community builders as well as lifelong learners (Mi, 2015). Librarians benefit from forging stronger connections and relationships with faculty in the classroom, while enhancing opportunities for their own professional development in the quickly evolving blended educational technology environment.

\section{Conceptual Framework/Design}

The FLC literature provides the general framework and structure for a targeted deeper dive into OER. This is a natural extension of the concepts of scholarship as conversation as well as information creation as a process which aligns well with the Association of College and Research Libraries' (ACRL) Information Literacy Framework (ACRL, 2015). Ongoing dialogue is important.

A basic concept underlying any FLC is that there is tremendous inherent value in learning from others. This is true in a traditional classroom setting with group discussions and applies in this situation when exchanging ideas and insights with professional colleagues. Shared interest in a topic is the only prerequisite for being part of the FLC. A designated group with the discipline of regular gatherings and dialogue is a proven time management technique which ensures some 
level of commitment and accountability.

These special interest groups can be tailored to accommodate any type of institution, mix of individuals, timeframe, or topic. In addition to yielding information about the chosen topic being studied, FLCs may also lay the groundwork for possible future interdisciplinary collaboration, mentoring, and partnerships. It is worthwhile to consider inclusivity, diversity, and equity when developing the community. Who might be underrepresented according to any demographic measures used?

Flexibility is a key attribute of most FLCs. Groups are generally based on an informally negotiated combination of the expectations of its members, and each gathering is shaped accordingly. It is accepted and celebrated that each individual brings to the table a unique set of professional experiences, subject matter expertise, technical prowess, focused interests, shortand long-term goals, and time and effort available to commit to this activity. Most are seeking inspiration and motivation, as well as knowledge. Most find that enthusiasm is contagious. The group dynamics can spark both individual energy and collective synergy.

Due to the way that OER are still evolving as part of the academic landscape, faculty perceptions of OER run the gamut. OER is a broad term and means different things to different people. An FLC environment is the perfect place to practice meeting people where they are. Discovering new and often unexpected connections can result when working outside of departmental or institutional silos. Ideally facilitators help foster the benefit of connecting people as well as imparting content. Trust from working together enables the OER FLC to agree on expected participation levels, establish some basic operating guidelines, and help pre-empt or resolve any potential misunderstandings.

\section{Development and Implementation}

Hosting an FLC under the auspices of a teaching and learning center, grant department, provost, dean or other sponsoring office provides organizational support which may seem daunting if individually-led. Helpful administrative support can include creating mailing lists, provisioning shared file space, and scheduling meeting rooms. Assistance with publicizing events and subsidizing refreshments are welcomed as well.

A teaching and learning center, or other office that can provide a pre-FLC orientation session, helps facilitators review general FLC history and best practices. There may be one or more facilitators who are appointed or volunteer. Prior experience with FLCs and a well-articulated and shared understanding of the goals and anticipated outcomes provide much stronger scaffolding than a loose community of practice. Lessons learned from other FLCs in other subject areas, with other goals, can strengthen the outcomes of the proposed group.

To assist with orientation, Cox (2009) created an "FLC Goals Inventory" to clarify specific characteristics that go into successful FLCs. These include emphasizing teaching, gaining more in-depth understanding on a specific topic, developing a sense of connection to others and to the institution, enhancing teaching effectiveness, and focusing on the scholarship of teaching, learning, and research. This opportunity to reflect on goals from a higher perspective before starting the FLC can help the facilitator identify specific objectives and deliverables for the 
program.

Those undertaking the FLC facilitator role will do well to spend time beforehand reflecting on why OER is a relevant topic for their students, faculty, and institution. Understanding and articulating how the FLC can further the adoption of OER, and the benefit of doing so on the campus at this time, will help others carry the message. Why is textbook affordability a hot topic? Why is the timing right for the department, institution, or system? What background, training, experience, energy, and connections can a potential facilitator bring to the initiative?

With a clear vision in hand, moving to more pragmatic steps will help get the FLC successfully launch. Identifying rules of engagement at the beginning can be very helpful. The rules of engagement may include widely agreed upon general principles for meetings and communication. Examples include: assuming that everyone comes to the community with good intentions, being present in the moment, listening to understand before speaking, encouraging clarifying questions, being open to changing viewpoints, ensuring everyone has a chance to speak, staying on task, and being sensitive about time (Ortquist-Ahrens \& Torosyan, 2008, p 21). The group also needs to plan how it wants to handle disagreement and disinterest.

Clearly describing objectives and outcomes helps build enthusiasm for the yearlong endeavor. There can be short term, long term, and interim milestones. The goals for the year may include items such as reviewing OER research (Clements, Pawlowski, Manouselis, 2015; Hilton, 2020), identifying current trends, and suggesting future directions. The impact of how OER is making a difference to students' learning is another rich vein to explore in the Scholarship of Teaching and Learning (SOTL). Which students benefit most, and why (Colvard, Watson, \& Park, 2018)?

There are many variations of openness along with challenges and opportunities on the road to OER adoption. Helping faculty develop a focused plan to move from pilot program to implementation and assessment works best when aligned with institutional, departmental, and individual objectives. Documenting success stories and building OER advocacy for campus stakeholders (faculty, staff, students, library, IT, bookstore, etc.) may be of interest for some FLCs. Similarly, developing a program for faculty and others new to OER should be welcome by all institutions.

There are many opportunities for group activities and programs. An example might be to offer facilitated training via online badge certification courses about OER (SUNY OER Services, 2018). It is typically easy to organize participation in an OER panel discussion for Teaching and Learning Day, Scholars Day, or other campus event. Faculty speaking to their peers almost always resonates better than administratively driven scenarios. Member voices strengthen the message. Consider hosting non-traditional events (e.g., 5-10 minute speed networking tables where faculty can demonstrate how they are using OER in a variety of courses and disciplines).

OER FLCs may include a mix of group and individual projects. Individual projects could include sharing self-initiated research efforts. Other efforts may be associated with surveying student opinions formally (e.g., surveys, focus groups, end of semester feedback sessions) and informally (e.g., whiteboard surveys, suggestion boxes, repositionable sticky note displays). Other activities may involve developing advocacy and promotion programs, or participating in OER poster sessions, presentations, seminars, or panel discussions at conferences (e.g., 
OTESSA, SUNY Conference on Instructional Technologies, Ed Tech Day, or more discipline specific venues).

Themes and topics for meetings, exercises, and activities depend on the interests of the group. Examples might include:

- conducting an environmental scan of relevant OER by subject area and updating LibGuides as appropriate

- $\quad$ examining incentives and barriers to OER adoption (Belikov \& Bodily, 2016)

- learning about the spectrum of OER licensing from most to least restrictive; hosting a speaker on copyright, Creative Commons, or other intellectual property issues

- inviting a discussion with the bookstore, library, IT, and other stakeholders. Consider including the tutoring and writing center, grants, internships, and other relevent units. Ask OER authors to talk about their experiences in creating materials. Pay special attention to the ways that student voices have been included in developing OER materials as co-authors, editors, and reviewers as one way to reduce disposable assignments

- planning or enhancing course materials (in various formats including textbooks, quizzes, supplemental interactives, and ancillaries), or entire courses, or open degree programs ( $Z$ degree)

- determining how to designate OER classes using low or no cost materials in course schedules (Clifton, DeFranco, \& Daly, 2020)

- connecting with existing campus opportunities to be part of Teaching and Learning Day (e.g., McCollough, Warren \& Harris, 2018), student scholar and research showcases, annual Open Access and Open Education Weeks, and other existing campus events that are aligned with, and contribute to, institutional mission and vision

- listening to and amplifying student voices whenever possible, including student involvement in OER textbook creation (Hill, 2019) as well as town halls, Textbook Broke campaigns, inclusive poster sessions, and advocacy efforts like student government, Student Public Interest Research Groups (PIRGS), service organizations, and clubs

- discussing inclusion of OER in Appointment, Promotion, and Tenure (APT) guidelines

- increasing the size of the community by thinking about how OER could best be used by students with disabilities, online students, traditionally underrepresented students, or those with limited technology access.

\section{Program Evaluation}

Evaluations were both formative and summative. They encouraged reflections on both the mechanics and dynamics of how the group functioned, as well as reflections on matters related to high impact practices for OER use (Einbinder, 2018). Formative evaluations were done throughout the year. In the current case, members were regularly asked for their input on topics for meetings. The facilitator was available, approachable, and appreciative of suggestions for the group. Thus, the cohort became a collaborative. In addition, the OER FLC met with the 
teaching and learning center director and other FLC facilitators during the year for quarterly check-ins which were useful for staying on track, discussing common issues and problems, and identifying potential solutions.

Summative evaluations comprised one-hour focus groups of faculty participants who were asked about what worked, what did not, and what could be changed in the future. A final report provided another opportunity to reflect on the year and review the work. The report was mostly qualitative in nature, providing insights and laying the groundwork for how the group's work could be translated into follow-on actions. It revisited the original goals of the group, and how time was spent.

Did the program meet all its goals? How was success measured? What is, can, or will be changed? Do metrics about the amount of OER materials used, number of courses taught, and depth of commitment by faculty advocates tell the whole story? Each member admitted individual professional development/growth that was appropriate for them, as well as some level of increased overall job satisfaction as a result. Several faculty members expressed interest in maintaining ties with the cohort going forward. Paying attention to evaluation results can help determine added value to the institution and inform the OER path forward.

Evaluation questions may be related to faculty and student satisfaction with OER, barriers and challenges in using OER, suggestions for changes or improvements in teaching and learning, additional ways that OER can be supported and sustained, and how to develop more advocates and champions. Eliciting feedback about the impact of OER during the pivot to online teaching caused by Covid-19 pandemic was of special interest. Since the pandemic began mid-way through the semester and course materials were already in place, the OER FLC members were able to continue using their course materials without much difficulty. Challenges with inconsistent technology and network availability were more common.

\section{Findings and Limitations}

The OER FLC had ambitious goals and not all could be accomplished in a year. The onset of COVID-19 made the timeline even more challenging, yet it also surfaced additional OER success narratives. Members focused on improving the digital accessibility of existing OER. They became more interested in ancillaries like quizzes and other interactive materials. Some also used the FLC opportunity to investigate open resources offered through professional associations and library collections from other disciplines.

Caveats and limitations included the size of the group. Cox (2001) recommends keeping the group size small for best results. Our FLC was somewhat fluid, and we were able to welcome new faculty members with OER interests who joined later in the year and brought additional perspective to those teaching global online courses.

The composition of the group also requires balance for best results. Including faculty who have not attained tenure is encouraged, although it is recognized that OER FLC participation may or may not be counted toward promotion. Since the FLC depends on a voluntary coalition of the willing, new untenured faculty may not have thought they had time to devote to an OER FLC. Participation in a group like this may be perceived to be a luxury for those with time. A diversity

Open/Technology in Education, Society, and Scholarship Association Journal: 2021, Vol. 1(1) 1-13 
of voices by age, gender, race, academic rank, teaching experience, etc., is ideal. Although FLCs are typically intended for full-time instructors, adjuncts and part time faculty exploring OER can offer additional perspectives and should be welcomed.

Messaging and communications need to avoid the appearance of group exclusivity. Handouts, elevator pitches, talking points, social media, reports, etc. need to be thoughtful and consider their audiences. Public communication should include accessibility accommodations such as closed captioning, alternative image tagging, and more, as appropriate. An OER group benefits from openly sharing information. Weaving news, updates and accomplishments into institutional strategic planning, priorities, and timelines is a skill worth cultivating (Early \& Holton, 2016).

There are also limitations imposed by the academic calendar. This is always a challenge for any group and work needs to be sequenced and planned. In this case there were 15 bi-weekly meetings per academic year. Interspersing deliverables throughout the year is generally preferred instead of producing a single year-end report or presentation. Keeping track of events, along with the number of people participating and their departments or disciplines, can be useful metrics for evaluation.

An additional challenge is sustaining long-term vision. Can the energy of the FLC be propelled into future practice at the instructor level (Tinnell, Ralston, Tretter, \& Mills, 2019)? Can its work be built into an ongoing OER advisory council? Can the OER FLC efforts be used to recruit new OER faculty, or be used to mentor new OER instructors?

\section{Discussion}

It is important to have some structure yet remain flexible with this endeavor. Taken at face value, the three words in the descriptive phrase "Faculty Learning Community" speak volumes. There are many names that could be given to a group sharing interest in a common subject or goals. Depending on the setting, it could be considered as a special interest gathering, an affinity group, an ad hoc committee, a support group, a club, a professional network of colleagues, or a deputized task force.

Concentrating on the purpose and function, not the descriptive title, is most relevant. One of the first things a facilitator needs to do is clarify a shared vision for the group and, with collaborative input, establish realistic expectations. What seems obvious to one person may not be so obvious to others.

During an era of scarce resources, an administrator may question whether an FLC on any topic is a necessity or a luxury. The answer will vary based on the needs of the institution at the time. However, FLCs usually generate distinct benefits in helping to ignite new ideas and programs in a way that is community-based, assists individual faculty to renew and refresh their teaching techniques, and provides a springboard for future innovation.

\section{Impact on Practice}

After a year, many participants were more committed, more engaged, and more prepared to move beyond finding and using OER materials to work toward more open pedagogy. Members were better able to evaluate publisher offerings, consider the impact of new models, and 
understand the need for flexibility and resilience. The group had greater recognition of other open alternatives, hybrid options, customizable solutions, and more. Although publishers may seem to be incorporating more components claiming to be open, the packaging can be misleading. The group was savvier about how some publishers are co-opting OER efforts and finding new ways to monetize OER.

The FLC group gained a better understanding of the value of librarians and how these professionals can help faculty (e.g., strategic searching, copyright, and Creative Commons licensing). Conversely, librarians obtained a better grasp of some of the pragmatic issues inherent in using OER such as broken hyperlinks, limited choices in some subject areas, and uneven tools for finding and evaluating OER materials. Technological advances, as well as the ever-changing academic landscape, are blurring the lines around job responsibilities.

Some FLCs have been proactive in creating deliverables including articles, blogs, webpages, OER toolkits, and LibGuides (Little, Fallon, Dauenhauer, Balzano \& Halquist, 2010) to directly impact teaching practice. OER materials themselves are becoming both more diffuse and more focused. There is a growing awareness of how OER materials and other efforts in open publishing can be helpful in preparing for the unexpected.

\section{Adapting to the Unexpected}

Many people in higher education were hit hard by the COVID-19 pandemic as instructors scrambled to move courses online mid-semester in the Spring of 2020. Although hard evidence is not readily available, there are anecdotal reports that OER courses fared better because they were purposely developed to use openly available materials, rather than textbooks. Not all students may have acquired textbooks in non-OER courses. This was an unexpected but fortuitous benefit of OER adoption. Also, the widespread, easy availability of online meeting tools like Zoom and Blackboard Collaborate meant that the OER FLC bi-weekly meetings could continue. Though moved to a virtual format, the ability to informally check in as a community with a small group of faculty members was valued among those who attended.

\section{Recommendations for Future Practice}

This article provides a facilitator's perspective in developing an OER FLC during 2019-20 in a mid-sized, public, comprehensive college. Lessons learned include:

1. Stay humble. Review the FLC literature as background. Learn and be inspired by those who have done similar things in the past. Do not re-create the wheel.

2. Provide motivation. Clearly describe intentions and expectations for the OER FLC to help others decide to join. What's in it for them? How can they benefit? Will relevant data be collected that can be shared in a group presentation, publication, webinar, or blog? How can experiences be best communicated at the student, department, school, and college level, and beyond? Consider who is not at the table and how to include them.

3. Plan logistics. Identify how the group keeps agendas and meeting notes. Create email lists, a learning management system group (e.g., Blackboard) or other structures for the members to share readings and other items ahead of time so they are ready from the first day the group meets.

4. Use backwards design. Keep desired outcomes and deliverables in mind from the beginning. Is the goal to write a grant, increase number of OER champions, or develop strategies for integrating OER into additional courses, entire departments, or specific programs? Prioritize these goals into "must do" and "not critical" categories.

Open/Technology in Education, Society, and Scholarship Association Journal: 2021, Vol. 1(1) 1-13 
5. Stay focused and maintain momentum. Keep moving to prevent loss of interest, share ideas for session subtopics.

6. Take periodic pulse of the group. Be prepared to learn how to pivot and adapt gracefully as needed. This means being ready to leave an established path for unexplored but beneficial intellectual detours. Know when and how to return to the task at hand.

7. Celebrate often. Consider how to appropriately celebrate both small and larger milestones, accomplishments, and successes.

8. Do not lose track of the calendar. Unplanned time can easily slip away. Time management can be critical to ensuring good outcomes.

9. Document success stories as well as lessons learned. Set an example of "walking the walk" by collecting open data and making available in open repositories. Provide research scaffolding, pilot projects, etc. for those who follow.

10. Have fun. Be sure to allow time for joy, laughter, and enjoyment. Nurture curiosity and wonder.

11. Share and express gratitude often. Develop empathy and good listening skills. Capture reflections for next time. Use the community to strengthen a culture of caring (Timmermans et al., 2018).

12. Share with the rest of the campus and beyond through social media, posters, presentations, panel discussions, invited speakers, connections to other campus events, planning activities and assessment initiatives.

13. Remember to listen thoughtfully. Encourage, and leave room for future inclusive connections related to OER advocacy, student involvement, and additional engagement strategies.

\section{Conclusion}

The FLC model provides a structured framework for supporting OER after initial program rollout and implementation. Curious instructors frequently want to know more about the benefits of OER for teaching and learning. For some, OER is a springboard to a deeper conversation about teaching methods and open pedagogy (Jhangiani, 2019). For new faculty this can be a just-intime way to think about how to organize and structure course content. For others, this is an opportunity to refresh and re-engage instruction with new ideas about educational delivery.

The FLC model is especially useful for enabling faculty to consider what happens next, after they have decided to adopt OER in their courses. How can instructors advocate for further OER use by others? How can they best share what they have learned in an ethical, open, and accessible manner? For many, participation in a faculty learning community is the beginning of a journey to explore the OER evidence and improve pedagogy.

\section{Author's Contributions}

Mary Jo Orzech completed all analysis and writing.

\section{Open Researcher and Contributor Identifier (ORCID)}

Mary Jo Orzech (D) https://orcid.org/0000-0002-9724-7215

\section{Funding}

The author gratefully acknowledges funding support from SUNY OER Services (oer.suny.edu).

10 Open/Technology in Education, Society, and Scholarship Association Journal: 2021, Vol. 1(1) 1-13 


\section{Ethics Statement}

Ethical review approved by the Institutional Review Board, The College at Brockport, State University of New York, Review \#MODCR00000111.

\section{Conflict of Interest}

The author declares no conflict of interest.

\section{Data Availability Statement}

Summary of focus group data available upon request.

\section{References}

Association of College \& Research Libraries. (2015). Framework for Information Literacy for Higher Education. http://www.ala.org/acrl/standards/ilframework

Bazeley, J., Haynes, C., Myers, C., \& Resnis, E. (2019). Avoiding the "Axe": Advancing affordable and open education resources at a midsize university. Journal of Librarianship and Scholarly Communication, 7, eP2259. https://doi.org/10.7710/2162-3309.2259

Bazeley, J., Waller, J., \& Resnis, E. (2014). Engaging faculty in scholarly communication change: A learning community approach. Journal of Librarianship and Scholarly Communication, 2(3), eP1129. https://doi.org/10.7710/2162-3309.1129

BC Open Ed. (2019). https://open.bccampus.ca

Belikov, O., \& Bodily, R. (2016). Incentives and barriers to OER adoption: A qualitative analysis of faculty perceptions. Open Praxis, 8(3), 235-246.

https://dx.doi.org/10.5944/openpraxis.8.3.308

Boise State University IDEA Shop. (2018). Call for applications: Faculty learning community for open educational resources (S2019). https://www.boisestate.edu/ctl-idea/2019-facultylearning-communities-flc/cfa-flc-oer-s2019

Burress, T., Mann, E., \& Neville, T. (2020). Exploring data literacy via a librarian-faculty learning community: A case study. The Journal of Academic Librarianship, 46(1), 102076. https://doi.org/10.1016/j.acalib.2019.102076

Clements, K., Pawlowski, J., \& Manouselis, N. (2015). Open educational resources repositories literature review: Towards a comprehensive quality approaches framework. Computers in Human Behavior, 51, 1098-1106. https://doi.org/10.1016/j.chb.2015.03.026

Clifton, A., DeFranco, T., \& Daly, M. (2020). Case studies: State University of New York. In S. Hare, J., Kirschner, \& M. Reed (Eds.), Marking Open and Affordable Courses: Best Practices and Case Studies. U. of T. Arlington Libraries. https://uta.pressbooks.pub/markingopenandaffordablecourses

Colvard, N.B., Watson, C.E., \& Park, H. (2018). The impact of open educational resources on various student success metrics. The International Journal of Teaching and Learning in Higher Education, 30(2), 262-276. http://www.isetl.org/ijtlhe/pdf/lJTLHE3386.pdf

Cox, M. D. (2001). Faculty learning communities: Change agents for transforming institutions into learning organizations. To Improve the Academy, 19(1), 69-93. https://doi.org/10.1002/j.2334-4822.2001.tb00525.x

Cox, M. D. (2004). Introduction to faculty learning communities. In M.D. Cox \& L. Richlin (Eds.), Building Faculty Learning Communities, New Directions for Teaching and Learning: No. 97, Jossey-Bass. pp. 5-23. 
Cox, M. D. (2009), Faculty learning community goals inventory. In Faculty Learning Community Program Director's and Facilitator's Handbook, Miami University. (p. 231-233).

Creative Commons. (n.d.). Open Education. https://creativecommons.org/about/programareas/education-oer

Early, J., \& Holton, V. (2016). Are Your Findings "Finding" Their Way to the Community? A Faculty Learning Community Approach to Broad Dissemination. VCU Scholars Compass. https://scholarscompass.vcu.edu/community resources/54

Einbinder, S. (2018). A process and outcome evaluation of a one-semester faculty learning community: How universities can help faculty implement high impact practices. InSight: A Journal of Scholarly Teaching, 13(1), 40-58. https://doi.org/10.46504/14201803ei

Faculty Learning Communities. (n.d.). Center for Teaching Excellence. Miami University. http://miamioh.edu/cte/faculty-staff/flcs

Grand Valley State University. (2019). Past Faculty Learning Communities (2018-2019). https://www.gvsu.edu/ftlc/past-faculty-learning-communities-2018-2019310.htm\#19W O3FLC

Hill, D. J. (2019)._Students find empowerment in creating their own textbook. UB Now. http://www.buffalo.edu/ubnow/stories/2019/02/kruger-students-textbook.html

Hilton, J. (2020). Open educational resources, student efficacy, and user perceptions: A synthesis of research published between 2015 and 2018. Educational Technology Research and Development, 68, 853-876. https://doi.org/10.1007/s11423-019-09700-4

Jhangiani, R. (2019). 5Rs for Open Pedagogy. https://thatpsychprof.com/5rs-for-open-pedagogy

Little, J.J., Fallon, M., Dauenhauer, J., Balzano, B., \& Halquist, D. (2010). Interdisciplinary collaboration: A faculty learning community creates a comprehensive LibGuide. Reference Services Review, 38(3), 431-444. doi: 10.1108/00907321011070919

Lumen Learning. (2020)._Lumen Learning acquires Faculty Guild's higher education assets. http://lumenlearning.com/announcements/announcement-2020-06-16-facultyguild

McCollough, A., Warren, J., \& Harris, C. (2018). Identifying and Developing Open Educational Resources (OER) for your Class. Innovations in teaching and learning conference proceedings, 18, George Mason University. https://doi.org/10.13021/G8ITLCP.10.2018.2170

Metropolitan State University of Denver. (2019). New FLCs explore philosophy, resources. https://www.msudenver.edu/early-bird/2019/01/28-flcs.shtml

Mi, M. (2015). Expanding Librarian Roles through a Librarian Initiated and Facilitated Faculty Learning Community. Journal of Library Administration, 55(1), 24-40. https://doi.org/10.1080/01930826.2014.978683

Ortquist-Ahrens, L., \& Torosyan, R. (2009). The role of the facilitator in faculty learning communities: Paving the way for growth, productivity and collegiality. Learning Communities Journal, 1(1), 1-34. https://digitalcommons.fairfield.edu/cae-facultypubs/3

Peer 2 Peer University (2015). Learning Circles Facilitator Handbook. https://www.p2pu.org/en/handbook

Pikula, K. (2018). Using OER learning circles as a support system for faculty to engage in open pedagogy in student/instructor authoring of OER textbooks and online courses. Minnesota Summit on Learning and Technology. https://ccaps.umn.edu/minnesotasummit-learning-and-technology/program/using-oer-learning-circles-support-systemfaculty 
Soodjinda, D., Parker, J. K., Ross, D. L., \& Meyer, E. J. (2014). CSU digital ambassadors: An empowering and impactful faculty learning community. Journal of Digital Learning in Teacher Education, 31(1), 35-42. https://doi.org/10.1080/21532974.2015.979634

SPARC (n.d.) Open Education Leadership Fellows Program. https://sparcopen.org/ourwork/open-education-leadership-program/2019-2020

SUNY OER Services. (2018). OER Community Course Experience. https://online.suny.edu/sunyoercommunitycourse

Timmermans, J. A., Bruni, C., Gorbet, R., Moffatt, B., Stubley, G., Williams, D., \& Holmes, T. (2018). The flourishing of care in a multidisciplinary faculty learning community. International Journal for Academic Development, 23(4), 367-373. https://doi.org/10.1080/1360144X.2018.1521335

Tinnell, T. L., Ralston, P. A., Tretter, T. R., \& Mills, M. E. (2019). Sustaining pedagogical change via faculty learning community. International Journal of STEM Education, 6(1), 1-16. https://doi.org/10.1186/s40594-019-0180

Wenger, E. (1998). Communities of practice: Learning, meaning and identity. Cambridge University Press.

Wiley, D. (n.d.) Defining the "Open" in Open Content and Open Educational Resources. http://opencontent.org/definition 